\title{
Sor Juana y los indios: loas y tocotines
}

\author{
ENRIQUe Flores \\ Centro de Estudios Literarios \\ Instituto de Investigaciones Filológicas
}

Soy la mujer aerolito que está debajo del agua.

MARÍA SABINA

En nuestro paisaje imaginario hay dos poetas visionarias: sor Juana y María Sabina. A sor Juana la podríamos llamar Juana Sabina — la Sabia. Y aunque nunca ejerció de curandera, sí conocía las yerbas mágicas de los indios y sintió que sus versos habían sido "hechizados" por ellas.

Hay, en efecto, unos versos de sor Juana - que Bernardo Ortiz de Montellano citó como epígrafe de su Primero Sueño, compuesto en 1930 - que hablan de una vertiente india de la magia de sor Juana. Los versos, de un romance epistolar inacabado, son muy tardíos: ${ }^{1}$

\author{
¿Qué mágicas infusiones \\ de los indios herbolarios \\ de mi patria, entre mis letras \\ el hechizo derramaron?
}

(Sor Juana 1988: 160)

\footnotetext{
${ }^{1}$ En la edición de Méndez Plancarte, el romance aparece en la sección "Otros romances epistolares (sin fechas conjeturables)” y lleva el número 51, con una apostilla: "que no se halló acabado" (Sor Juana 1976a: 158). Castorena, el anotador, añade: "Este romance se halló así, después de su muerte, en borrador y sin mano última” —y se refiere a ella como el "Sol, aun ya moribundo" (448).
} 
Sor Juana se refiere a las yerbas mágicas de los curanderos populares. Las mismas que Montellano invoca en su poema — combinando el folclor, el asombro y el automatismo:

Para el romero mortal, veneno de tres olores, el manzano es hospital de flores.

Tallo de mano hechicera, grano de ajonjolí, para el mal de ojo: gusano de seda, abrojo, reptil.

Contra la sombra viruela, mañana del alfiler, cerilla de la luciérnaga, ojo de pez.

Aroma de la llonédula para vértigos de ver, médulas de hierba nueva para querer.

(Ortiz de Montellano: 57-58). ${ }^{2}$

"Maravillosa síntesis", dice Méndez Plancarte en una nota, "de los mágicos zumos de Méjico en la poesía de sor Juana” (1988: 448). Y refiere las "mágicas infusiones" o hechizos verbales a una obra de Valéry: Charmes - y a otro romance que alude a otra planta mágica: la quina: "cáscara del árbol llamado quarango, la qual es mui útil en la medicina” (Aut.).

${ }^{2}$ Sobre el automatismo, los conjuros y lo sonámbulo en la poesía de Montellano, $c f$. Flores, 2003: 45 ss. Un villancico de sor Juana — "Un herbolario extranjero"- alude a las "virtudes secretas" de ciertas plantas: la "hierba sánalo-todo", la hierbabuena, la "hierba santamaría", la "hierba santa", la manzanilla, la "celidonia" ("que aclara la vista"), la salvia (que "la lengua habilita"), el romero, la "siempreviva", la mejorana ("contra la pozoña") y la "yerba de la Puebla”, tan venenosa. El poema pregona las virtudes de la Virgen — "hierba bendita" - como "contrayerba" (Sor Juana 1976b: 21-22). 
¿Esas sustancias mágicas, se pregunta sor Juana, han podido nublar la inteligencia de los poetas europeos (y de Perú o Nueva Granada), admiradores de ella? ¿Alucinan? Pero los versos de sor Juana son nítidos: sus "letras" han sido hechizadas por los indios, su canto está imbuido de un hechizo - "derramado" en él, como un brebaje, por los magos indígenas. Hasta podría preguntarse si no son ellos los que inspiran su canto y ella es sólo un vehículo.

"No llegaba a ocho años la madre Juana Inés, quando, porque la ofrecieron por premio un libro, riqueza de que tuvo siempre sedienta codicia, compuso para una fiesta del Santísimo Sacramento una loa, con las calidades que requiere un cabal poema" (Calleja: 18). El relato del padre Calleja, biógrafo de sor Juana, va precedido de otras frases no menos reveladoras:

La primera luz que rayó de su ingenio fue azia los versos españoles, y era muy racional de quantos la trataron en aquella edad tierna ver la facilidad con que salían a su boca o su pluma los consonantes y los números; assí los producía, como si no los buscara en su cuidado, sino es que se los hallasse de valde en su memoria (17).

Si "la primera luz" de su ingenio "fue azia los versos españoles", la segunda sufrió el influjo —o el "hechizo" — de los versos nahuas. Pues la curiosa noticia que ofrece el padre Calleja se confirmó recientemente con el hallazgo de una loa satírica bilingüe, en español y en náhuatl, que Juana Inés compuso a los ocho años y está dividida en dos partes, una de las cuales mezcla ambas lenguas mientras la otra las alterna en un diálogo de un bachiller y un indio. "Loa de la infancia" o "papelillo de la infancia": así la designan sus descubridores. ${ }^{3}$

${ }^{3}$ Cf. el dossier de Letras Libres, con la crónica del hallazgo (Vallejo Villa), la traducción de la loa y un análisis filológico de la misma (Díaz Cíntora). Localizada en los archivos de la Colección Goupil y catalogada por Boturini en su Museo indiano hacia 1740, se titulaba: "Loa satírica en una comedia de la festividad de Corpus hecha y realizada en Tlayacapan en el año de 1682" (aunque este año no sea por fuerza el de su primera puesta en escena). El manuscrito es parte de una colección de "loas en verso megicano": Mercurio encomiástico en la excelentísima lengua mexicana o náhuatl. Un tal Antonio Pérez de la Fuente y Quijada lo copió por mandato del cacique de Tlayacapan: "Hechas en di- 
Según el padre Calleja, Juana Inés compuso la loa en la hacienda de Panoayan, en la jurisdicción de Amecameca. Y aunque en el título de la loa se dice que fue "representada en Tlayacapan", en sus versos sólo se menciona a Amecameca — "un pueblo [...] de indios" por entonces, cuyo gobernador era elegido "entre los caciques de la región" (Vallejo Villa: 81). Este carácter indígena de la región entera se refleja en la humildad retórica típica de la loa:

\begin{tabular}{|c|c|}
\hline $\begin{array}{l}\text { Cenca huel nipinaubtíhuitz, } \\
\text { con sobrada desvergüenza, }\end{array}$ & ${ }^{*}$ Apenadísima vengo \\
\hline sobre aqueste cuaubtlapechtli & * escenario \\
\hline donde zanoixtlapachteca; & ${ }^{*}$ apenas quepo entera \\
\hline amo ixpantzinco pidiendo & ${ }^{*}$ de vuestra parte \\
\hline $\begin{array}{l}\text { huel tetepitzin licencia } \\
\text { para decir dos palabras }\end{array}$ & ${ }^{*}$ muy pequeńita \\
\hline $\begin{array}{l}\text { ipanpatica comedia } \\
\text { que en esta fiesta del Corpus, }\end{array}$ & ${ }^{*}$ a favor de la \\
\hline es cierto, titlamacehua. & ${ }^{*}$ traemos a escena \\
\hline Y porque amo ammitalhuizque & ${ }^{*}$ no nos digáis \\
\hline ca zazan tihistriones, nébuatl & ${ }^{*}$ que no somos más que / yo \\
\hline onicchiuh inin disculpa & ${ }^{*}$ presento esta \\
\hline ipanpatica tofiesta, & * a favor de la \\
\hline porque huel techxixicoa & ${ }^{*}$ nos hacen burla \\
\hline mochipa inin caxtilteca. & ${ }^{*}$ siempre estos españoles \\
\hline Señores, huel tetlacolti, & ${ }^{*}$ es una pena \\
\hline inin quichibua, de veras, & * eso que hacen \\
\hline tonanual, porque cualani & ${ }^{*}$ mala suerte / se enojan \\
\hline ihuan zazan techmapehua; & ${ }^{*}$ nomás nos dan empujones \\
\hline $\begin{array}{l}\text { quitotihuitz: —Quita allá, } \\
\text { que no sois para comedias. }\end{array}$ & ${ }^{*}$ vienen a decir \\
\hline
\end{tabular}

versos tiempos desde el año de 1682, que en Tlayacapan me hizo hacer don Juan Hipólito Cortez Quetzalcuauhtli y Tequantepehua este encomio al Santísimo Sacramento" (Vallejo Villa: 80). Como lo sugiere un documento de la Sala del Crimen, el copista es un "mestizo achinado" que "les hace [a los indios] escritos y les aconseja e industria". Y concluye el descubridor de la loa: "Se le encuentra asociado con caciques y posiblemente trataba de reivindicar los derechos de éstos y de los indios. Y también se interesó por preservar los testimonios escritos de lengua mexicana" (81). 
Estos indios, ¿tlein quimati? ¡Aic quichihua cosa buena!
* ¿qué saben?

*Nunca hacen

(“Loa satírica mixta...” 2001 I: vv. 1-24)

La que habla es una niña, señala el filólogo, y "la niña que habla es [...] española" (Díaz Cíntora: 70). Lo que no impide que, con "desparpajo", se burle de ciertos bachilleres:

Pues cequintin bachilleres,

huel filósofos de lengua, hualhui yuqui in cazadores: ixcopan motlanquaquetza, poniendo el un pie en la China auh in occe Amecamecan; buel yuhqui tochtli quimótlaz, motlanquaquetza en la iglesia inin sofísticos tlaca, inin doctores de Atenas. ¿Tlein mach amo techilhuizque? Porque, zan ica inon pehua, in zan teca tlatlatoa, zazan nohuian quicuepa imixtotomatlachiéliz, óquic la comedia empieza. In tla ye opeuh, zanye niman, con mil gestos mосиесиера; cuix haciendo admiraciones, quimahtlotalia in cejas; niman quitoa: - Por fuerza, más que por ganas que tenga, vengo yo a esta moledera [...].
* algunos

* muy

* vienen como los

* en público se arrodillan

* y el otro en Amecameca

* como conejos echados

* se arrodillan

* estos / hombres

* estos

* Qué no nos van a decir

* apenas esto empieza

* nomás hablan de la gente

* nomás vuelven dondequiera

* sus estúpidas miradas

* mientras

* Si ya empezó, luego luego

* se dan vuelta

* $\mathrm{o}$

* alzan en arco las

* luego dicen

${ }^{4}$ Modifico la puntuación de Díaz Cíntora, cuya traducción adapto un poco, poniendo en cursivas los fragmentos originales en náhuatl: "Apenadísima vengo, / con sobrada desvergüenza, / sobre aqueste escenario / donde apenas quepo entera; / de vuestra parte pidiendo / muy pequeñita licencia / para decir dos palabras / a favor de la comedia / que en esta fiesta del Corpus, / es cierto, traemos a escena. / Y porque no nos digáis / que no somos más que histriones, / presento esta disculpa / a favor de la fiesta, / porque nos hacen burla / siempre estos españoles. I Señores, es una pena / eso que hacen, de veras, I mala suerte, porque se enojan / y nomás nos dan empujones; / vienen a decir: —Quita allá, / que no sois para comedias. / Estos indios ¿qué saben? / ¡Nunca hacen cosa buena!” 
Pues esto, para nosotros, es lo mismo que tinieblas.

(“Loa satírica mixta...” 2001 I: vv. 87-118)

“Tinieblas": teológicas y de la lengua, que Juana Inés habla con una familiaridad que le permite satirizar a una vieja (arrugada y esquelética, "como la bruja Medea") y a una mulata capataza de indios (grotesca mezcla de "membrillo cocho" y de africana de Guinea):

Y si no, ximottilican:
ohualla nican ce vieja,
in cuix otlamahuizoco
yoqui in tlahuépoch Medea;
in zazan opipilichauh,
como un esqueleto inezca.

\author{
* vamos a ver \\ * ha venido aquí una \\ * acaso a hacerse famosa \\ * como la bruja \\ * nomás está llena de arrugas \\ * que aparezca
}

(“Loa satírica mixta...” 2001 I: vv. 63-68)

Tihuiantzitzin, ichpopochtin: occe huallauh, quaichcayéhuatl, in tlaco membrillo cocho ${ }^{7}$ auh in octlaco guinea; in cuix notlamahuizoa ic noteilhui in molienda: —Eso que los indios hacen, ipara eso los de mi tierra!
* Vengan, muchachas: otra viene

* con piel de oveja en la cabeza

* la mitad

* y la otra mitad

* se siente acaso importante

* porque ordena la

5 "Pues algunos bachilleres, / muy filósofos de lengua, / vienen como los cazadores: / en público se arrodillan, / poniendo el un pie en la China / y el otro en Amecameca; / como conejos echados, / se arrodillan en la iglesia / estos sofísticos hombres, / estos doctores de Atenas. I ¿Qué no nos van a decir? I Porque, apenas esto empieza, I nomás hablan de la gente, I nomás vuelven dondequiera / sus estúpidas miradas, / mientras la comedia empieza. I Si ya empezó, luego luego, / con mil gestos se dan vuelta, / o haciendo admiraciones, I alzan en arco las cejas; / luego dicen: - Por fuerza, / más que por ganas que tenga, / vengo yo a esta moledera [...]. Pues esto, para nosotros, / es lo mismo que tinieblas".

${ }^{6}$ Son los versos de la bruja: "Y si no, vamos a ver: / ha venido aqui una vieja, / acaso a hacerse famosa / como la bruja Medea; / nomás está llena de arrugas; / como un esqueleto que aparezca".

${ }^{7}$ La expresión "membrillo cocho" designaba, en los contratos, un color de la piel de los esclavos. 
¡Que lo hacen con bizarría

y no aquesta borrachera!

(“Loa satírica mixta...” 2001 I: vv. 73-82) ${ }^{8}$

Para el cronista, los últimos versos "aluden a que la autora no es de Amecameca":

Y así es verdad, pues la niña Juana Inés nació en la hacienda de San Miguel Nepantla, jurisdicción de la parroquia de Chimalhuacán, en Chalco, cabecera de varios pueblos [...] de filiación xochimilca; no así los de Amecameca, que eran chalcas. Sor Juana, años más tarde volverá a expresarse en términos similares, cuando dice: "de los indios herbolarios de mi patria" (Vallejo Villa: 119).

En el siglo Xvir, la patria es "el lugar, ciudad o país en que se ha nacido" (Aut.). Y si sor Juana escribe "los indios herbolarios de mi patria", habla de los indios xochimilcas de la región de San Miguel Nepantla, el "lugar" en que había nacido. (Juan Badiano, "indio de Xochimilco" y "lector en latín" del Colegio de Santiago Tlatelolco, tradujo el libro náhuatl del herbolario azteca Martín de la Cruz: Libellus de medicinalibus indorum herbis, una obra enteramente impregnada de "vigoroso contenido mágico"; López Austin: 83.) En lo que se equivoca el cronista es en interpretar esos versos como una exclamación de Juana Inés, y no como una exclamación de la mulata, reminiscente, quizá, de los ritos y los bailes africanos:

Guineo. Cierta especie de baile u danza que se executa con movimientos prestos y accelerados, y gestos ridículos y poco decentes. Es baile propio de negros, por cuyo motivo se le dio este nombre (Aut.).

Aunque la condena sea expresada por la capataza mulata, no hay que olvidar que la fiesta de los indios no es ajena, en la loa de Juana Inés, a la intoxicación y la "borrachera".

8 "Vengan muchachas: otra viene / con piel de oveja en la cabeza, / la mitad membrillo cocho / y la otra mitad guinea; / se siente acaso importante / porque ordena la molienda: / —Eso que los indios hacen, / ipara eso los de mi tierra! / ¿Que lo hacen con bizarría / y no aquesta borrachera!" 
La segunda parte de la loa — dialogada — es, precisamente, un canto ritual indígena a dos voces y en dos lenguas. La voz del indio irrumpe con delicadeza, "cargada de flores del color de los chalchihuites", 9 esparciéndolas por "la firme y hermosa redondez de la tierra":

INDIO: Machalchiuhxochitimampan on papaquilcatlamati, in qualnezololiuhcáyotl icayo in cemanahuactli.

EsPañol: ¿Quién con estilo tan nuevo y tan extraño lenguaje interrumpe los aplausos de tantas felicidades?

(“Loa satírica mixta...” 2001 II: vv. 5-12)

Un "estilo nuevo" y un "extraño lenguaje" dan el tono de la aparición del indio. Es un "canto que alegra como bolitas de chalchihuites", y que dice con gran dulzura: "Laudate omnes gentes. Nadie nos vence a nosotros, hombres de tierra, aunque seamos macehuales":

INDIO: Ihuan ipan inon cuicatl chalchiuhcoyoltepapacti, ca Laudate omnes gentes contzopelitoa yamanqui, amo techtlaquabuilia, in timochtin in tehuantin in titlalticpac titlaca, macihui timacehualtin.

(“Loa satírica mixta...” 2001 II: vv. 49-56)

9 “Chalchihuite. Del mexicano chalchiuitl, 'esmeralda basta' (Molina). Hay dudas de lo que realmente entendían por chalchihuitl los indios de Nueva España. Unas veces se toma como nombre propio de una piedra verde, que se cree haber sido el espato fluor: otras como genérico de diversas piedras. De todos modos, los indios estimaban y usaban mucho el chalchihuitl [...]. Algunos traían chalchihuitl, que quiere decir piedra preciada (Descripción de Ameca, 1579)" (Santamaría, s.v.). 
El "afecto de sor Juana por los indios, de sobra conocido" (Díaz Cíntora: 70), lleva ya a la niña Juana Inés a proponer un argumento extraño, por su materialismo y su bajeza - si es cierto que no hay "cosa tan baja como pedir de comer". Y es: que la "mayor fineza" de Cristo no fue la eucaristía, sino la encarnación, y que, si insiste el español en hablar del pan, entonces, como apunta Díaz Cíntora, la "mayor fineza" sería la multiplicación de los panes. "Con cinco panes", recuerda el indio, "alimentó a cinco mil hombres y mujeres, sin contar a los nińos pequeños, que eran innumerables. Y quedó todavía pan; mucho hay en el cesto":

INDIO: $\quad$ Yub mochihua, caye qualli,
yece no xonyolmaxilti,
ca iquac inon mahuizauhqui
cenhuey teotlamahuizolli.
In totemaquixticatzin
oquimochihuilitzino,
inca macuilli tlaxcalli,
in oquimotlaqualtili
tepachihuitlicatanqui,
macuillica cemmilpitin
oquichtin ibuan cihuame,
auh ca ne in pipiltotonti,
amo tehuantlapohualtin.
Ca nel amo pohualoni
ipampa ca cenca miactin,
aub in ye omochiuh inin
teochalchiubtlamahuizauhqui.

(“Loa satírica mixta...” 2001 II: vv. 112-128) ${ }^{10}$

Y esta parte propiamente ritual, litúrgica, mistérica, de la loa — pues su asunto es el misterio de la eucaristía - culmina con una invocación a la entidad divina que aglutina, que sintetiza o que crea en náhuatl los "nombres [indígenas] de Cristo": "toteoyeyotlatocatzin" ("divino señor nuestro"); "teotlatoani Jesucristo" ("divino señor Jesucristo”), o volvien-

10 "Está bien, pero considera esa maravilla, ese grandísimo milagro: que con cinco panes alimentó, hasta saciarse completamente, a cinco mil hombres y mujeres, sin contar a los chiquillos, que eran innumerables. Y cuando se hizo ese precioso milagro, quedó todavía pan: mucho hay en el cesto". 
do a las flores preciosas y chalchibuites, "teochalchiuhcachimaltzin" ("divino escudo de jade"):

$\begin{array}{ll}\text { INDIO: } & \text { ¿Tlein oc nel toconitozque } \\ & \text { toteoyeyotlatocatzin } \\ & \text { teotlatoani Jesucristo } \\ \text { ca teochalchiuhcachimaltzin? } \\ \text { ¿Tlein nel nozo tiquitozque? } \\ \text { Ca nel amo tlein ticmati. } \\ {[\ldots]} \\ \text { In tocnotetepitonyo } \\ \text { ¿tlein mixpantzinco quitláliz? }\end{array}$

(“Loa satírica mixta...” 2001 II: vv. 155-166)

“QQué diremos aún?”, pregunta el indio hacia el final del diálogo. Y en los últimos versos vuelve a interrogarse, dejando por sola respuesta al silencio: "¿Qué hemos de decir? Que no sabemos nada. Nuestra miserable pequeñez ¿qué puede ofrecer en tu presencia?”

El "universo sonoro" en el que creció Juana Inés, dice Patrick Johansson, era muy peculiar. Sus tonos, timbres, intensidades y variantes sonoras nutrieron la lengua de sor Juana. Había los "espańoles" hablados por criollos, negros, indios y mestizos, pero también el náhuatl:

En efecto, tanto San Miguel Nepantla, ranchería donde nació, como Panoayan, la hacienda que arrendaba su familia y donde creció, están situados en una región donde se hablaba el náhuatl hasta hace poco. Podemos pensar que la convivencia con los peones indígenas y sus familias hizo que sor Juana se familiarizara tempranamente con esta lengua [...]. Más tarde, en el convento de San Jerónimo, permaneció en estrecho contacto con hablantes nahuas, ya que la mayoría de las sirvientas eran de esta estirpe étnica (Johansson, 1995: 461).

Este "bullicio" era mayor en las fiestas que reunían a todos esos grupos étnicos, en las que reinaba una "polifonía" lingüística —un "concierto de voces" que resuena aún en los juegos de villancicos (Johansson 1955: 462). El aliento multicultural de la sociedad novohispana se ma- 
nifiesta de manera muy nítida en esas construcciones verbales y en las celebraciones litúrgicas que les servían de marco. Los villancicos nahuas o tocotines, los "villancicos de negro", los "guineos", los "puertorricos", los "mestizos", ponían en juego aspectos étnicos, musicales, dancísticos, poéticos, gestuales y tonales del México del siglo Xvir. Poetas como sor Juana pudieron explorar, ahí, por ejemplo, las posibilidades de la lengua náhuatl, con su estructura polisintética, flexible, que facilita la composición de bloques verbales compactos y la fusión de las palabras en "masas sonoras", trabajando, dice Johansson, la lengua como un "telar", haciendo surgir el sentido de una "urdimbre" y alcanzando, así, una "epifanía de sentido sensible" (461-462). Como los tocotines de sor Juana: cuando no están compuestos en náhuatl, se escuchan en ellos "ecos" fonéticos y gramaticales nahuas (463); cuando están en náhuatl, "lo afectivo se expresa mejor con las variaciones del tono, de la acentuación, del timbre o de los gestos" (473). Un extraño "magnetismo de afinidades y coincidencias" crea "marañas semánticas", juegos de palabras y de sentidos prácticamente inextricables (478).

El primer tocotín de sor Juana es el que compuso para la fiesta de la Asunción, año de 1676. Está escrito enteramente en un náhuatl de "notable gracia y fluidez", como afirma el padre Garibay, gran traductor del náhuatl (Sor Juana 1976b: 365). Sigue a un diálogo o cantar entre dos "negrillos" y va precedido de una entrada que le sirve de introducción a la danza:

\author{
Los mejicanos alegres \\ también a su usanza salen, \\ que en quien campa la lealtad \\ bien es que el aplauso campe; \\ y con las cláusulas tiernas \\ del mexicano lenguaje, \\ en un tocotín sonoro \\ dicen con voces süaves.
}

(Sor Juana 1976b: 16-17)

Vemos entrar, así, al atrio de la iglesia, a un grupo de danzantes aztecas similares, quizá, a los concheros que aún bailan las llamadas "danzas de la conquista". (La concha es una guitarra de diez cuerdas hecha de un caparazón de armadillo; la acompañan el huébuetl, el teponaztle y los 
"huesos", unas sartas de semillas atadas a los tobillos.) ${ }^{11}$ Salen vestidos "a su usanza” y cantando en náhuatl — "con las cláusulas tiernas / del mexicano lenguaje" - , una lengua que, a oídos de sor Juana, brilla por sus "voces suaves", aunque las apaguen los "sonoros" ritmos — "toco, toco, totoco, toco" - del tocotín, como apunta Méndez Plancarte:

Tocotín: danza azteca, y su letra, en nombre acaso onomatopéyico de sus ritmos: "toco, toco, totoco, toco". Ya el presbítero bachiller Francisco Bramón introduce a "el Reino Mejicano... con una tilma de plumería y oro..., y un rico escudo con sus armas, que son el águila sobre el tunal", y bailando con seis "caciques", al son del "teponaxtle", una "vistosa danza, mitote o tocotin” (Sor Juana: 1976b, 364).

El tono del tocotín de la Virgen es familiar, como los versos a los "parientes", que pueden traducirse así: “¿Acaso nunca regresarás a la tierra? Tus parientes sufrirán mucho":

\section{¿Amo nozo quenman \\ timotlalnamictiz? \\ In moayolque mochtin \\ huel motilinizque.}

(Sor Juana 1976b: 17)

Uso la versión de Johansson (1995: 473 ss.), que pone el énfasis en el tono y habla de las "ambiguas resonancias" de esta estrofa, que entraña, para él, la amenaza "latente" de maltratar o de matar al Niño, y para mí es un eco más de las "tiernas cláusulas" mexicanas:

\section{Mochichibualayo \\ oquimomitili, \\ tla motemictía \\ ihuan tetepitzin.}

(Sor Juana 1976b: 17)

${ }^{11}$ Cf. El disco Danzas de la conquista, con grabaciones de campo, y el folleto que lo acompaña. 


\section{Con tu leche \\ lo hartaste; \\ si no, se moría \\ muy chiquito.}

(Johansson, 1995: 476)

Mochichihualayo: ¿cómo no evocar aquí a la chichigua o nodriza indígena, que a través de siglos nutrió con su leche a los niños criollos, como sor Juana? María aparece, así, como una imagen borrada, y tierna, de su propia infancia: como una chichigua. "Chichigua. Voz del idioma mexicano, muy usada antiguamente; pero inútil, pues tenemos la castellana nodriza, que ha prevalecido, y desterrado de la buena sociedad a la otra”. ${ }^{12}$ El tocotín de san Pedro Nolasco fue compuesto por sor Juana un año después, en 1677. Va precedido por los "latinajos" de un bachiller y por el baile —un "puerto rico" - de un negro que entra cantando "al son de un calabazo", el cacambé (Méndez Plancarte 1976b: 373):

¡Tumba, la-lá-la; tumba, le-lé-le;

que donde ya Pilico, escrava no quede!

¡Tumba, tumba, la-lé-le; tumba la-l-a-la;

que donde ya Pilico, no quede escrava!

(Sor Juana 1976b: 39)

Más que una danza indígena, este "tocotín mestizo" es el cantar de un indio que — como en la "jácara del mestizo" de una de las barriadas de México - acompaña su plegaria con los “ecos desentonados” de una guitarra, ${ }^{13}$ y entra cayéndose de borracho al escenario:

Púsolos en paz un indio

que, cayendo y levantando,

${ }^{12}$ La definición del lexicógrafo es elocuente. Cf. también: "Chichi. Del mexicano chichi, mamar [...]. Vulgarmente, mama, teta, el pecho de la hembra, el seno. Utilízase principalmente en plural" (Santamaría, s.v.).

${ }^{13}$ Cf. Flores, 1991: 20-21. Las "glosas" de sor Juana dicen: "Con aquesta ocasión, pues, / entraron a celebrarle / de lo mejor de los barrios / multitud de personajes. // El primero fue un mestizo / que, con voces arrogantes, / le disparó estos elogios / disfrazados de coraje" (Sor Juana II: 56). También la "valona" de sor Juana: "Dadle licencia, señora, / a mi voz desentonada” (Sor Juana 1976b: 108-109). 


\begin{abstract}
tomaba con la cabeza
la medida de sus pasos;

el cual en una guitarra,

con ecos desentonados,

cantó un tocotín mestizo

de espańol y mejicano.
\end{abstract}

(Sor Juana 1976b: 41)

El tono, aquí, es de jácara: el tono del guapo, del "valentón”. Como cuando un topil (o alguacil) lo manda aprehender por no pagar el tributo y él le da con un palo en la cabeza:

\author{
Huel ni machicáhuac; \\ no soy hablador: \\ no teco qui mati, \\ que soy valentón [...]. \\ También un topil \\ del gobernador, \\ caipampa tributo \\ prenderme mandó. \\ Mas yo con un cuábuitl \\ un palo le dio \\ ipam i sonteco: \\ no sé si morió.
}

(Sor Juana 1976b: 42)

Como anota Méndez Plancarte, el cantar es una "mezcla de náhuatl y de castellano algo amestizado": las "incrustaciones aztecas" conviven con "formas aindiadas" (375). Las "flores de muerto" o sempual xúchil — "veinte flores" — nos regresan al ritual y a la herbolaria:

$$
\begin{aligned}
& \text { Yo al santo lo tengo } \\
& \text { mucha devoción, } \\
& \text { y de sempual xúchil } \\
& \text { un xúchil le doy. }
\end{aligned}
$$

(Sor Juana 1976b: 42) 
El tocotín de san José, compuesto en 1690, no es un baile ni un canto: es un tocotín "entremesado" — representado- en una brevísima pieza escénica. Se trata de una adivinanza puesta por un indio, en una tradición que entronca con los zazanilli de los antiguos nahuas:

INDIO: Yo también, quimati Dios, mo adivinanza pondrá, que no sólo los dotore habla la Oniversidá [...]. ¿Qué adivinanza? ¿Oye osté? ¿Cuál es mejor san José?

(Sor Juana 1976b: 142)

Para los aztecas, dice Patrick Johansson, las adivinanzas involucran, más allá de su carácter "jocoso", un significado "críptico o esotérico", cuando no "una función iniciática y adivinatoria" (2004: 3-4). Sólo el iniciado era capaz de captar ese lenguaje - tonalpouhqui o lector de los destinos; tícitl, médico, herbolario, chamán (37). Es la lengua sagrada de los sacerdotes mayas —el "lenguaje esotérico de Zuyuá" - y la lengua de la adivinanza popular:

-Zazan tleino, huipiltitich. Tómatl.

—¿Qué cosa y cosa? Tiene el huipil muy apretado. El tomate.

-Zazan tleino, xoxouhqui xicaltzintli, mumúchitl ontemi. Acca quitaz tozazaniltzin, tlacanenca ilhuicatl.

- ¿Qué cosa y cosa? Una jícara azul llena de maíz tostado. Para quien vea nuestra adivinanza, no puede ser más que el cielo.

(Johansson 2004: 49 y 53)

“¿Cuál es mejor san José”?, pregunta el indio en su español aindiado. Y el "doctor" y uno de los colegiales exclaman: “iGran disparate!" “iTerrible! / [...] ¿Cómo es posible?”:

INDIO: $\quad$ Espere osté, so doctor:

¿no ha visto en la iglesia osté

junto mucho san José, 
y entre todos la labor

de Xochimilco es mijor?

(Sor Juana 1976b: 143)

El indio les explica, así, cuál es el "mejor san José” — desde un punto de vista que a menudo llamamos "idolátrico", pero que es, en realidad, artesanal, material, sensible. Por lo bien labrado, el mejor san José es “¡el de la parroquia de Xochimilco!” (Sor Juana 1976b: 425).

A diferencia de la "Loa de Juana Inés", la "Loa para 'El divino Narciso"” es un canto ritual que introduce una pieza más amplia, representada en la corte de Madrid e impresa en el año de 1690: El divino Narciso. Si el auto sacramental alegoriza el misterio eucarístico y recurre a la fábula pagana de Narciso, la loa que le sirve de entrada es un tocotín indígena:

Sale el Occidente, indio galán, con corona, y la América, a su lado, de india bizarra: con mantas y cupiles [sic], al modo que se canta el tocotín. Siéntanse en dos sillas; y por una parte y otra bailan indios e indias, con plumas y sonajas en las manos, como se hace de ordinario esta danza; y mientras bailan, canta la Música ("Loa para 'El divino Narciso"” 1976a: 3).

Ningún otro tocotín de sor Juana posee la estructura ritual de esta loa, que, a pesar de que no involucra ni una sola palabra en náhuat, flota sobre el arquetipo de un ritual azteca:

MúsicA: Nobles mejicanos, cuya estirpe antigua de las claras luces del Sol se origina [...], ¡venid adornados de vuestras divisas [...], y en pompa festiva, celebrad al gran Dios de las Semillas!

(“Loa para 'El divino Narciso”" 1976a: vv. 1-14) 
Estos dos últimos versos son los que van a imprimirle su ritmo repetitivo al canto o "himno" de sor Juana —una auténtica pieza etnopoética del siglo Xviı. Como señala Méndez Plancarte en sus notas a la loa, su fuente mitológica pudo ser la Monarquía indiana, de fray Juan de Torquemada. Ahí encontramos (libro VI, caps. XVI y XLIV) varias referencias al Sol, origen de la "antigua estirpe" de los indios — como canta la loay único "Dios verdadero":

Estos indios infieles tenían conocimiento de un Dios, al qual llamaban Criador, Hacedor y Conservador de todas las cosas, el qual nombre no es posible convenir a otro que al que lo es verdadero [...]. Puesto que [...] tenían infinidad de dioses e ídolos que reverenciaban, sobre todos ellos tenían por maior y más poderoso al Sol, y a este dedicaban el maior y más poderoso y sumptuoso templo (Torquemada: 32 y 33 ).

Según ese mito de la creación solar, el hombre había sido engendrado en Texcoco:

Dicen que, estando el Sol a la hora de las nueve, hechó una flecha en el dicho término y hiço un hoio, del qual salió un hombre que fue el primero, no teniendo más cuerpo que de los braços arriba, y que después salió de allí la muger entera. Y preguntados cómo avía engendrado aquel hombre, pues él no tenía cuerpo entero, dijeron un desatino y suciedad, que no es para aquí (Torquemada: 79).

Los indios, dice Torquemada, tenían dioses de oro, de plata, de cobre, de barro, de palo: "otros de masa y otros de diversas semillas" (32). Como los gentiles, "tenían un dios para el grano, todo el tiempo que estuviese sembrado y escondido en la tierra, sin nacer" — un dios subterráneo (33). Pero el dios indígena de sor Juana demanda sangre y sacrificios:

\author{
Música: $\quad$ Y pues la abundancia \\ de nuestras provincias \\ se le debe al que es \\ quien las fertiliza, \\ ofreced devotos [...] \\ todas las primicias. \\ ¡Dad de vuestras venas \\ la sangre más fina, \\ para que, mezclada,
}




\author{
a su culto sirva; \\ y en pompa festiva, \\ celebrad al gran Dios de las Semillas!
}

(“Loa para 'El divino Narciso'” 1976a: vv. 15-28)

Huitzilopochtli, el Sol, el "gran Dios de las Semillas": cada vez que se repiten esas últimas líneas del canto, vuelven los bailes y las sonoridades indígenas (voces, percusiones) a la corte madrileña en la que se escenifica la loa. El monólogo de "Occidente", vestido con traje indio, como "indio galán, con corona” (un penacho, quizá), es un eco de Torquemada:

Occidente: Pues entre todos los dioses que mi culto solemniza, aunque son tantos, que sólo en aquesta esclarecida ciudad regia de dos mil pasan, a quien sacrifica en sacrificios crüentos de humana sangre vertida, ya las entrańas que pulsan, ya el corazón que palpita; aunque son (vuelvo a decir) tantos, entre todos mira mi atención, como a mayor, al gran Dios de las Semillas.

(“Loa para 'El divino Narciso'” 1976a: vv. 29-42)

Y "América", "india bizarra" ataviada de mantas y huipiles, ${ }^{14}$ le canta a ese mismo dios solar que fertiliza las sementeras y guarda a la semilla oculta en el interior de la tierra, como el sol al caer la noche. Ese dios que reclama "sangre humana", vertida en "sacrificios cruentos", entregando a los sacrificados a terribles actos de canibalismo ritual.

14 "Huipil. (Del azteca huipilli.) Antigua prenda de la mujer azteca, camisa de algodón, sin mangas, descotada, larga hasta las caderas y ancha, con bordados, adornos y bellas labores. Úsanlo hoy todavía las indias de Méjico y Centroamérica” (Santamaría, s.v.). Sor Juana habla de cupiles. 
AMÉrICA: Ese dios que su protección no limita sólo a corporal sustento

de la material comida, sino que después, haciendo manjar de sus carnes mismas (estando purificadas antes, de sus inmundicias corporales), de las manchas el alma nos purifica.

Y así, atentos a su culto, todos conmigo repitan:

Música: ¡En pompa festiva, celebrad al gran Dios de las Semillas!

(“Loa para 'El divino Narciso”" 1976a: vv. 60-72)

La semejanza con la comunión católica es igualmente terrible, y así lo entiende sor Juana, que, al final de ese discurso casi etnológico, renueva los cantos y bailes — los ritos de la fertilidad del "gran Dios de las Semillas". No carece de significado que sor Juana nombre así al dios azteca: es una traducción creadora que hace más concreto poéticamente al dios.

El rito al que alude sor Juana, como lo señala en sus notas Méndez Plancarte, viene de Torquemada (libro vi, cap. XxxviII). Vale la pena releerlo detenidamente, imaginando la fascinación de sor Juana ante la descripción del rito y su entusiasmo por las raras analogías:

Demás de la imagen y figura que en el templo maior de México tenían puesta a su falso y abominable dios Huitzilupuchtli (como ya hemos dicho), hacían cada año otra, confeccionada y mezclada de diversos granos y semillas comestibles, la qual se formaba de esta manera. En una de las salas más principales y curiosas del templo (que era cerca de su altar y cu), juntaban muchos granos y semillas de bledos y otras legumbres, y molíanlas con mucha devoción y recato, y de ellas amasaban y formaban la dicha estatua, del tamaño y estatura de un hombre. El licor con que se rebolvían y desleían aquellas harinas era sangre de nińos que para este fin se sacrificaban; cuyo intento era de notar, en la simplicidad y inocencia de la criatura, la de el dios que representaba la dicha estatua. Después de formada, la tomaban en palmas los sacerdotes y sátrapas, y con grande reverencia y estimación la subían al cu y altar que le tenían mui compuesto y adereçado, asistiendo a este acto todos los ministros y sonando 
las trompetas y otros instrumentos que hacían mucho y mui gran ruido, y iban delante muchos, bailando y cantando (Torquemada: 71).

Pasado el día de la consagración de aquel diabólico y infernal pan y masa, no podía tocarle nadie ni entrar en su capilla, sino sólo el sumo sacerdote [...]. Y luego subían a los míseros hombres a lo alto y sacrificábanlos, comenzando por los cautivos en guerras y acabando aquel horrendo acto con los esclavos cebones para aquello comprados, sacándoles los corazones y arrojándolos a los pies del ídolo. Todo este día era de grandísima fiesta y regocijo, en el qual los sacerdotes tenían mucho cuidado de guardar la dicha estatua, velándola toda la noche, con mucha vigilancia [...]. Otro día, de mañana, bajaban la dicha estatua, y puesta en pie en una sala [...], tomaba un dardo Quetzalcóhuatl, en cuio remate tenía un casquillo de pedernal, y tiraba al ídolo al pecho, con el qual le pasaba, y el ídolo caía. La qual ceremonia se hacía diciendo que era matar al dios Huitzilopuchtli para comer su cuerpo. Luego acudían los sacerdotes, y uno de ellos le sacaba el coraçón y dábalo al rei y a los otros; hacían dos pedaços el cuerpo, y la una mitad daban a los de este Tlatelulco, los quales lo repartían, mui por migajas, entre todos los de los barrios, en especial a los mancebos soldados (sin dar a las mugeres nada de la masa del ídolo) Lo que quedaba a los de la parte de México, llamada Tenuchtlitlan, repartían en quatro barrios [...], y daban de él a los hombres, así grandes como pequeños, y niños de cuna. Y esta era su manera de comunión [...], y llamábase esta comida Teoqualo, que quiere decir: Dios es comido (72-73).

Todo está ahí: las semillas, la sangre, los cultos, los bailes y los cantos. La muerte del dios, su sacrificio, y el espacio escénico — real y, a la vez, simbólico - en que se produce el canibalismo ritual. Habría que olvidar las disputas teológicas aducidas por el editor de la loa (en aras de la eterna justificación de la conquista: la extirpación de los sacrificios) para decir, con Wittgenstein, lo que parece comprender sor Juana — que "el hombre es un animal ceremonial"; que "la magia descansa siempre en la idea del simbolismo y el lenguaje" (15); que lo "siniestro" de esa práctica deriva de su "naturaleza interna" (37), lejana y cercana de las nuestras; que "lo siniestro" radica en "el carácter mismo de estos hombres" (39). Como concluye Wittgenstein, "aquí sólo se puede describir y decir: así es la vida humana” (13):

¿De dónde viene, en suma, lo profundo y siniestro de los sacrificios humanos? ¿Serán, pues, sólo los sufrimientos de la víctima lo que nos im- 
presiona? [...]. No, lo profundo y siniestro no son obvios cuando sólo sabemos la historia de la acción externa, sino que nosotros los introducimos nuevamente, a partir de una experiencia interna (Wittgenstein: 41 y 43).

Pero volvamos a la loa. Si la primera escena constituye un canto ritual, la segunda es una especie de batalla: una representación de la conquista - una guerra, otra forma ritual. La "Religión", vestida como "dama española”, y el "Celo”, “de capitán general”, “armado”, entran escoltados por un grupo de soldados españoles. Son las milicias contra "la Idolatría”. Hay que imaginar, aquí, el ruido metálico de las armaduras yuxtaponiéndose a la música de los indios, los pasos militares y el ritmo del tocotín, la "cuchilla", las "plumas y sonajas":

Celo: $\quad$ Pues ya levantado el brazo, ya blandida la cuchilla traigo para tus venganzas [...].

(Salen, bailando, el Occidente y América, y acompañamiento y Música, por otro lado.)

Música: ¡Y en pompa festiva, celebrad al gran Dios de las Semillas!

Celo: $\quad$ [...] Pues lleguemos, que en sus torpes ritos está entretenida.

Música: $\quad \mathrm{Y}$ en pompa festiva, celebrad al gran Dios de las Semillas!

(“Loa para 'El divino Narciso”" 1976a: vv. 83-99)

La batalla escénica se entabla entre la danza ritual indígena y la guerra santa de los conquistadores. En este punto, cobra relevancia un factor tonal, un elemento de modulación casi musical de la lengua que me parece remitir a la lengua náhuatl: a "las cláusulas tiernas del mexicano lenguaje". Sor Juana, sabedora de que en la corte madrileña pocos apreciarían las sonoridades nahuas de sus tocotines, inventa un "tono" fiel a esa lengua, una "versión” a la española de esas "cláusulas", que contrasta dramáticamente con la violencia imperativa y las órdenes de las milicias cristianas. Es una lengua hecha de preguntas y de asombros, que poco 
tiene que ver con las miserias o lo demoniaco y mucho con la contemplación poética:

RELIGIón: Dejad el culto profano a que el demonio os incita. ¡Abrid los ojos! Seguid la verdadera doctrina que mi amor os persüade.

Occidente: ¿Qué gentes no conocidas son éstas que miro, ¡cielos!, que así de mis alegrías quieren impedir mi curso?

AmÉrica: ¿Qué naciones nunca vistas quieren oponerse al fuero de mi potestad antigua?

Occidente: ¡Oh tú, extranjera belleza; oh tú, mujer peregrina! Dime quién eres, que vienes a perturbar mis delicias.

(“Loa para 'El divino Narciso”" 1976a: vv. 104-119)

Llega, así, un debate violento sobre la "guerra santa" y la "justa conquista". Por un lado, la voluntad férrea de la "Religión" de "reducir" estas provincias a su culto; por el otro, una bárbara religión natural que tacha de "imposible" y "locura" las pretensiones cristianas:

AmÉrica: ¡Buena locura pretendes!

Occidente: ¡Buen imposible maquinas!

AmÉrica: Sin duda es loca; ¡dejadla, y nuestros cultos prosigan!

Música $\quad ¡ Y$ en pompa festiva

y ellos: $\quad$ celebrad al gran Dios de las Semillas!

(“Loa para 'El divino Narciso”" 1976a: vv. 124-129)

El del "Celo" es el lenguaje de la violencia. Y del castigo y del "temor”. Del grito: 
Occidente: ¿Quién eres, que atemorizas con sólo ver tu semblante?

Celo: $\quad$ El Celo soy. ¿Qué te admira? Que, cuando a la Religión desprecian tus demasías, entrará el Celo a vengarla, castigando tu osadía.

Ministro de Dios soy, que viendo que tus tiranías han llegado ya a lo sumo, cansado de ver que vivas tantos ańos entre errores, a castigarte me envía. Y así, estas armadas huestes que rayo de acero vibran, ministros son de su enojo e instrumentos de sus iras.

(“Loa para 'El divino Narciso”” 1976a: vv. 130-155)

Y el lenguaje de "Occidente" es el del canto, el de los cultos e himnos a lo divino:

Occidente: ¿Qué Dios, qué error, qué torpeza, o qué castigos me intimas?

Que no entiendo tus razones ni por remotas noticias, ni quién eres tú, que osado a tanto empeño te animas como impedir que mi gente en debidos cultos diga:

Música: $\quad ¡ Y$ en pompa festiva, celebrad al gran Dios de las Semillas!

(“Loa para 'El divino Narciso”" 1976a: vv. 156-165)

Lo que intenta el "Celo" es "turbar el sosiego" de los indios, interrumpir los cultos:

América: Negad el oído y vista a sus razones, no haciendo 


\author{
caso de sus fantasías; \\ y proseguid vuestros cultos, \\ sin dejar que advenedizas \\ naciones, osadas quieran \\ intentar interrumpirlas. \\ Música: ¡Y en pompa festiva, \\ celebrad al gran Dios de las Semillas!
}

(“Loa para 'El divino Narciso”" 1976a: vv. 175-183)

Hacia su fin, la segunda escena de la loa trae consigo la "interrupción" de la danza. La batalla se desencadena y las armas españolas triunfan sobre las indígenas. Los arcabuces derrotan a las flechas indias; las "cajas y clarines" se imponen al huéhuetl y los teponaztles; los caballos aterrorizan a las gentes. Y en el fragor guerrero, la admiración, la exclamación, la interrogación, la metáfora, la imagen mítica, siguen siendo las claves de la mirada india:

Celo: $\quad$ ¡Toca el arma! ¡Guerra, guerra!

(Suenan cajas y clarines.)

Occidente: ¿Qué abortos el cielo envía contra mí? ¿Qué armas son éstas, nunca de mis ojos vistas? ¡Ah, de mis guardas! ¡Soldados: las flechas que prevenidas están siempre, disparad!

AmÉrica: ¿QQué rayos el cielo vibra contra mí? ¿Qué fieros globos de plomo ardiente graniza? ¿Qué centauros monstrüosos contra mis gentes militan?

(Dentro:) ¡Arma, arma! ¡Guerra, guerra! ¡Viva España! ¡Su rey viva!

(“Loa para 'El divino Narciso”" 1976a: vv. 184-200) 
Aparentemente, la guerra derrota a la poesía y las armas interrumpen el ritual. Hay que decir, sin embargo, que las imágenes rituales contrapuestas a la guerra de los españoles son frecuentes en las crónicas indígenas. Allí está el Libro Doce del Códice Florentino, con las alucinantes escenas del "Tecolote-Quetzal” (cap. xxxviıI), el capitán tintorero de oficio, investido con los atavíos de esa figura mítica capaz de sumir en "pavor" a sus enemigos a la hora crucial de la batalla. O la escena arquetípica de la masacre del Templo Mayor, cuando, en las fiestas de Huitzilopochtli, y en el "patio del dios", los soldados españoles irrumpen a sangre y fuego, silenciando el sonido de los "atabales" y acallando los cantos y los bailes:

Tomaron a un gran capitán de nombre Opochtzin, tintorero de oficio. En seguida lo revistieron, le pusieron el ropaje de tecolote de quetzal, que era insignia del rey Ahuizotl. Le dijo Cuauhtemoctzin:

-Esta insignia era la propia del gran capitán, que fue mi padre Ahuizotl. Llévela éste, póngasela y con ella muera. Que con ella espante, que con ella aniquile a nuestros enemigos. Véanla nuestros enemigos y queden asombrados [...].

Ya va en seguida en tecolote de quetzal. Las plumas de quetzal parecían irse abriendo. Pues cuando lo vieron nuestros enemigos, fue como si se derrumbara un cerro. Mucho se espantaron todos los espańoles: los llenó de pavor: como si sobre la insignia vieran alguna otra cosa (Sahagún: 158-159).

Pues así las cosas, mientras se está gozando de la fiesta, ya es el baile, ya es el canto, ya se enlaza un canto con otro, y los cantos son como un estruendo de olas, en ese preciso momento los espańoles toman la determinación de matar a la gente. Luego vienen hacia acá, todos vienen en armas de guerra [...].

Inmediatamente entran al patio sagrado para matar a la gente. Van a pie, llevan sus escudos de madera, y algunos los llevan de metal y sus espadas.

Inmediatamente cercan a los que bailan, se lanzan al lugar de los atabales: dieron un tajo al que estaba tañendo: le cortaron ambos brazos. Luego lo decapitaron: lejos fue a caer su cabeza cercenada.

Al momento todos acuchillan, alancean a la gente y les dan tajos, con las espadas los hieren. A algunos les acometieron por detrás; inmediatamente cayeron por tierra disparadas sus entrańas. A otros les desgarraron la cabeza: les rebanaron la cabeza, enteramente hecha trizas quedó su cabeza.

Pero a otros les dieron tajos en los hombros: hechos grietas, desgarrados quedaron sus cuerpos. A aquéllos hieren en los muslos, a éstos en las 
pantorrillas, a los de más allá en pleno abdomen. Todas las entrańas cayeron por tierra. Y había algunos que aun en vano corrían: iban arrastrando los intestinos y parecían enredarse los pies en ellos. Anhelosos de ponerse en salvo, no hallaban a dónde dirigirse.

Pues algunos intentaban salir: allí en la entrada los herían, los apuñalaban. Otros escalaban los muros: pero no pudieron salvarse. Otros se metieron en la casa común: allí se pusieron en salvo. Otros se entremetieron entre los muertos, se fingieron muertos para escapar. Aparentando ser muertos, se salvaron. Pero si entonces alguno se ponían en pie, lo veían y lo acuchillaban (Sahagún: 116-117).

¿Cómo no escuchar las resonancias de pasajes como éstos en la loa de sor Juana y en su "visión" de la conquista? El asombro, la ceremonia y el espanto, la "eficacia mágica" de los rituales, el ambiente onírico, el lenguaje poético, todos estos elementos construyen la "loa de la conquista", sin olvidar la referencia directa, ineluctable, al episodio del templo, con su énfasis en lo festivo y lo palpable: los cantos divinos, los bailes, bañados en sangre.

La violencia, sin embargo, está elidida en la loa de sor Juana: "Trabada la batalla", indica una acotación, "van entrándose por una puerta, y salen por otra huyendo los indios, y los españoles en su alcance; y detrás, el Occidente retirándose de la Religión y América del Celo" (10-11). “¿No es mejor que todos mueran?", pregunta el "Celo" en la tercera escena. Y aunque la "Religión" prefiere "que se conviertan y vivan", los indios responden con una afirmación de la libertad y la resistencia, con los ecos del canto ritual que estructura la loa:

\author{
AMÉrica: Si el pedir que yo no muera, \\ y el mostrarte compasiva, \\ es porque esperas de mí \\ que me vencerás, altiva, \\ como antes con corporales, \\ después con intelectivas \\ armas, estás engańada; \\ pues aunque lloro cautiva \\ mi libertad, ¡mi albedrío \\ con libertad más crecida \\ adorará mis deidades!
}


Occidente: Yo ya dije que me obliga a rendirme a ti la fuerza; y en esto, claro se explica que no hay fuerza ni violencia que a la voluntad impida sus libres operaciones; y así, aunque cautivo gima, ¡no me podrás impedir que acá, en mi corazón, diga que venero al gran Dios de las Semillas!

(“Loa para 'El divino Narciso”" 1976a: vv. 226-246)

Lo que se anuncia es una persistencia clandestina, una continuidad de los cultos — similar a la continuidad de los cantos en la puesta en escena- después de la conquista. En la loa no hay espacio ni para la "conquista espiritual" ni para el exterminio: la resistencia nace de una afirmación de lo sagrado, de lo palpable, de la hierofanía. Un dios "que fertiliza los campos"; que trae las lluvias y los frutos; que, como en los cultos del maíz, se ofrece como alimento. Todo ello en un lenguaje, repito, poético y ritual, que contrasta con la "causalidad diabólica" del lenguaje de la "Religión" — o al menos del que usa internamente, en un aparte de la loa-, y al que caracterizan no sólo las abstracciones teológicas, sino también un verbo emponzoñado y esa teoría del "remedo" diabólico tan extraña a las analogías de sor Juana:

Occidente: Es un dios que fertiliza los campos que dan los frutos; a quien los cielos se inclinan, a quien la lluvia obedece $y$, en fin, es el que nos limpia los pecados, y después se hace manjar, que nos brinda.

Religión: ¡Válgame Dios! ¿Qué dibujos, (aparte) qué remedos o qué cifras de nuestras santas verdades quieren ser estas mentiras? ¡Oh cautelosa serpiente! ¡Oh áspid venenoso! ¡Oh hidra, 


\author{
que viertes por siete bocas, \\ de tu ponzońa nociva \\ toda la mortal cicuta! \\ ¿Hasta dónde tu malicia \\ quiere remedar de Dios \\ las sagradas maravillas?
}

(“Loa para 'El divino Narciso”" 1976a: vv. 250-272)15

Estamos en la escena cuarta, catalizadora del sincretismo. Ante la resistencia de los indios, la "Religión" opta, en efecto, por asimilar la cosmovisión indígena con una "visión" del universo emparentada con el neoplatonismo y arraigada en analogías secretas, enigmas, metáforas y traslaciones poéticas. Prodigios, signos ocultos, correspondencias, hierofanías; "un Dios no conocido" (v. 287) ilumina el mundo, fertiliza los campos y las "sementeras":

$\begin{array}{ll}\text { RELigión: } & \text { Pues si el prado } \\ & \text { florido se fertiliza, } \\ & \text { si los campos se fecundan, } \\ & \text { si el fruto se multiplica, } \\ & \text { si las sementeras crecen, } \\ & \text { si las lluvias se destilan, } \\ & \text { todo es obra de su diestra: } \\ \text { pues ni el brazo que cultiva, } \\ \text { ni la lluvia que fecunda, } \\ \text { ni el calor que vivifica, } \\ \text { diera incremento a las plantas, } \\ \text { a faltar su productiva } \\ \text { providencia, que concurre }\end{array}$

${ }^{15}$ Cf. las oportunas anotaciones de Méndez Plancarte: "Remedos. Ya [fray Gerónimo de] Mendieta [...] decía: 'Parece haber tomado el maldito demonio oficio de mona, procurando que su [...] infernal congregación de idólatras [...] remedase [...] a la Iglesia católica' (II, cap. XIV) [...]. Y cf. también José de Acosta [...], Historia natural y moral de las Indias, cap. XI: "De cómo el demonio ha procurado asemejarse a Dios en el modo de ... los sacramentos", y cap. xxiv: "De la manera con que el demonio procuró en Méjico remedar la fiesta de Corpus Christi y la comunión” (Sor Juana 1976a: 507). 
a darles vegetativa

alma.

(“Loa para 'El divino Narciso”" 1976a: vv. 307-321)

Un universo mágico, poético, ritual, asoma en el sincretismo de sor Juana. Y la voz de los indios no olvida (a contracorriente de esta transmutación simbólica, presente ya en el rito de Torquemada) que el traslado involucra a un dios palpable y un sacrificio sangriento:

AMÉRICA: Dime, ¿̇será tan propicia

esa deidad, que se deje

tocar de mis manos mismas,

como el ídolo que aquí

mis propias manos fabrican

de semillas y de sangre

inocente, que vertida

es sólo para este efecto?

(“Loa para 'El divino Narciso” 1976a: vv. 323-329)

OcCidente: Y dime, aunque más me digas:

¿será ese Dios, de materias

tan raras, tan exquisitas,

como de sangre que fue

en sacrificio ofrecida,

y semilla, que es sustento?

(“Loa para 'El divino Narciso”" 1976a: vv. 348-353)

La idolatría, el sacrificio, la teofagia ritual: esos tres elementos transgresores van a "precipitarse" en el recipiente de la misa cristiana - forma teatral por excelencia, como dice T. S. Eliot (57) - y de la eucaristía. Allí está el sacrificio humano (vv. 356-358); allí están la carne y la sangre (v. 362); allí, "las semillas del trigo" (vv. 360-361). Allí está, finalmente, como lo apunta Méndez Plancarte, esa "admirable alusión" al rito del Teocualo: "Dios es comido".

En la última escena, concluida la batalla teológica de la conquista, la loa recobra el papel de pregonera del auto sacramental, y articulando 
una franca analogía entre la alegoría teatral y la idolatría de los indios, se dispone a levantar el tablado y montar el espectáculo:

ReLigión: Pues vamos. Que en una idea metafórica, vestida de retóricos colores, representable a tu vista, te la mostraré; que ya conozco que tú te inclinas a objetos visibles [...].

(Escena quinta)

Celo: ¿En qué forma determinas representar los misterios?

ReLigión: De un auto en la alegoría quiero mostrarlos visibles.

(“Loa para 'El divino Narciso”" 1976a: vv. 401-419)

Pero el tablado levantado por sor Juana es, en cierto modo, un tablado imaginario, fantástico. En él se va a establecer el paralelo entre la mitología pagana y la indígena: entre el mito griego de Narciso, las fiestas de Huitzilopochtli y el misterio de la eucaristía. Ídolos aztecas o griegos ocultan, y revelan, la misma "maravilla". Pero, en la loa de sor Juana, hay un aspecto fantasmal que se expresa en la distancia entre dos mundos y en la "ausencia" de su autora. Una autora ausente y unas Indias puramente "intelectivas" asedian el escenario:

Celo: $\quad$ ¿Pues no ves la impropiedad de que en Méjico se escriba y en Madrid se represente? [...] ¿Cómo salvas la objeción de que introduces las Indias y a Madrid quieres llevarlas?

Religión: Como aquesto sólo mira a celebrar el misterio, y aquestas introducidas personas no son más que 


$$
\begin{aligned}
& \text { unos abstractos que pintan } \\
& \text { lo que se intenta decir, } \\
& \text { no habrá cosa que desdiga, } \\
& \text { aunque las lleve a Madrid: } \\
& \text { que a especies intelectivas } \\
& \text { ni habrá distancias que estorben } \\
& \text { ni mares que les impidan. }
\end{aligned}
$$

(“Loa para 'El divino Narciso”" 1976a: vv. 443-472)

Al final, esos "abstractos" besan las reales plantas. Y "América" (la voz, ya, de sor Juana) pide perdón "a sus ingenios", humildemente, como se acostumbraba hacer en la loa:

AMÉricA: ... a quien humilde suplica el mío, que le perdonen el querer con toscas líneas describir tanto misterio.

(“Loa para 'El divino Narciso”" 1976a: vv. 481-485)

Pero sólo para continuar el tocotín, la danza ritual, el canto del Dios de las Semillas - el "verdadero Dios de las Semillas", al que le canta sor Juana (con un cacique azteca y un conquistador) "intelectivamente" vestida de "india bizarra", ataviada con mantos y huipiles:

Occidente: ¡Vamos, que ya mi agonía quiere ver cómo es el Dios que me han de dar en comida,

(Cantan la América y el Occidente y el Celo:)
diciendo que ya
conocen las Indias
al que es verdadero
Dios de las Semillas!
$\mathrm{Y}$ en lágrimas tiernas
que el gozo destila, repitan alegres
con voces festivas: 
Todos: $\quad \begin{aligned} & \text { ¡Dichoso el día } \\ & \text { que conocí al gran Dios de las Semillas! }\end{aligned}$
(Éntranse bailando y cantando.)
(“Loa para 'El divino Narciso”" 1976a: vv. 486-498)

En el capítulo xuviII, último del libro vi, Torquemada compendiaba otros muchos "agüeros y supersticiones" que tenían los indios, entre ellos los vinculados con la ingestión del dios:

Los totonaques de tres en tres años mataban tres niños, sacábanles los corazones, y de la sangre que de allí salía, y de cierta goma que llaman ulli, que sale de un árbol en gotas blancas y después se vuelve negra, como pez, y de ciertas semillas, las primeras que salían en una huerta que en sus templos tenían, hacían una confección y masa. Esta tenían por cosa sagrada [...]. Llamaban a esta masa Toyoliaytlaquatl, que quiere decir: Manjar de nuestra vida. El sacerdote maior hacía ciertas ceremonias en una poca de agua, quando consagraba la estatua de el ídolo Huitzilopuchtli, en México, que era hecho de masa, de todas semillas, amasadas con sangre de niños y niñas que le sacrificaban (83).

Estas palabras y estos rituales inspiran el sincretismo alegórico de la loa y el canto sacrificial de sor Juana al "gran Dios de las Semillas". Sacrificios cruentos, aunque a veces, externamente, revistieran un aspecto incruento u ocultaran en el humo la ingestión del dios:

También hacían unos idolitos chiquitos, de semilla de bledos o ceniços, o de otras yerbas, y ellos mismos se los comían. Otros dicen que a una yerba que dicen picietl (y los espańoles llaman tabaco) la tenían algunos por cuerpo de una diosa, que nombraban Cihuacoatl. Y a esta causa, puesto que sea algo medicinal, se debe tener por sospechosa y peligrosa, maiormente viendo que quita el juicio y hace desatinar al que lo toma [...]. La carne de los sacrificados ante sus dioses tenían en gran veneración, por poquito que alguno de ella alcançace (83). 
Una extraña resonancia de estos ritos puede escucharse en las "veladas" mazatecas de María Sabina, "la sabia de los hongos". Como señala Gordon Wasson, refiriéndose a las "visiones" de la chamana indígena y a las de los chamanes "consultados", en 1629, por fray Hernando Ruiz de Alarcón en su Tratado de las supersticiones de los naturales de la Nueva España, existen "notables correspondencias" entre el dios que aparece en el relato del fraile novohispano (y que según el experto no es otro que Piltzintecu$h t l i$, el "Nobilísimo Infante", que recibe "el don de los divinos hongos" en una escena mítica del Códice Vindobonensis), y ese joven "vigoroso, atlético, viril, especie de Apolo mesoamericano" de que habla María Sabina, y al que llama "Jesucristo" (Gordon: 13). Piltzintecuhtli / Jesucristo son los hongos divinos, los hongos mágicos: los "niños", Nixti, o "niños santos", Nixti-santo, los "santitos" o las "cositas", Ndi-santo, Ndi-tzojmi, "el pequeño que brota”, $N$ di-xi-tjo (Estrada: 27, n. 4). Son otra forma de ingestión del dios o de comunión eucarística. Son la "sangre de Cristo":

Los niños son la sangre de Cristo. Cuando hablamos de las veladas lo hacemos en voz baja y para no pronunciar el nombre que tienen ( $N d i-x i-$ tjo) los llamamos cositas o santitos. Así los llamaban nuestros antepasados (Estrada: 74).

Tiempo después, supe que los hongos eran como Dios. Que daban sabiduría, que curaban las enfermedades y que nuestra gente hacía muchísimos ańos que los tomaban. Que tenían poder. Que eran la sangre de Cristo (36).

Teofagia, sacrificio. Pero el poder de los niños es el del canto y el del "Lenguaje":

Mi Lenguaje nadie me lo enseñó, porque es el Lenguaje que los niños santos dicen al entrar en mi cuerpo. Quien no nace para ser sabio, no puede alcanzar el Lenguaje aunque haga muchas veladas. ¿Quién podría enseñar un Lenguaje así? [...] El Lenguaje de Dios [...]. Yo curo con el Lenguaje, el Lenguaje de los niños santos. Cuando ellos aconsejan sacrificar pollitos, se colocan encima de las partes donde duele. El resto es el Lenguaje $(78,45)$. 
Como sor Juana en su Respuesta, María Sabina se remonta a su más tierna infancia para contarnos, si no la historia de su "inclinación", sí la historia de su "iniciación" poética:

El sabio Juan Manuel había llegado para curar al tío Emilio Cristino; por vez primera, yo presenciaba una velada con los niños santos. Esto lo comprendí más tarde. Vi cómo el sabio Juan Manuel encendía las velas y hablaba con los dueños de los cerros y a los dueños de los manantiales. Vi cómo repartía los hongos contándolos por pares, que fue entregando a cada uno de los presentes, incluyendo al enfermo. Más tarde, en completa oscuridad, hablaba, hablaba y hablaba. Su lenguaje era muy bonito. A mí me gustó. Por momentos, el sabio cantaba, cantaba y cantaba. No comprendía exactamente las palabras pero a mí me agradaba. Era un lenguaje diferente al que nosotros hablamos en el día. Era un lenguaje que, sin comprenderlo, me atraía. Era un lenguaje que hablaba de estrellas, de animales y de otras cosas desconocidas para mí (34).

Las mágicas virtudes de los hongos se derraman en el canto de María Sabina, india "yerbera", "doctora", vehículo de la palabra, brotada, hechizada en el "pequeño que brota":

Porque soy la mujer sabia en medicina

Porque soy la mujer yerbera

Porque soy la mujer que brota

Soy la mujer que puede ser arrancada, dice

Soy la mujer doctora, dice

Soy la mujer hierbera, dice

La palabra que brota del cuerpo es como el hongo que brota de la tierra. Una forma de comunión capaz de hacer encarnarse a la palabra (con los pruritos del misterio cristiano):

Las cositas son las que hablan. Si digo: "Soy mujer que sola caí / Soy mujer que sola nací", son los niños santos quienes hablan. Y dicen así porque brotan por sí solos. Nadie los siembra. Brotan porque así lo quiere Dios. 
Por eso digo: "Soy la mujer que puede ser arrancada", porque los niños pueden ser arrancados, y ser tomados... Deben ser arrancados tal y como son arrancados. No deben ser hervidos ni nada. No se les necesita hacer más. Como son desenterrados, así deben ser tomados. Con todo y tierra. Deben ser comidos por completo, porque si por descuido se tira un pedazo, los niños preguntan al estar trabajando: “¿Dónde están mis pies? ¿Por qué no me comiste por completo?” Y ordenan: “¿Busca el resto de mi cuerpo y tómame" (61).

Aunque analfabeta, María Sabina es la mujer del libro. Y el libro brota de la tierra:

Tomo pequeño que brota y veo a Dios. Lo veo brotar de la tierra. Crece y crece, grande como un árbol, como un monte [...]. Otras veces, Dios no es como un hombre: es el Libro. Un libro que nace de la tierra (50).

María Sabina habla con los dioses entre bailes y cervezas (90). Le gusta la música:

Soy la mujer tamborista

Soy la mujer trompetista

Soy la mujer violinista

Pero es, sobre todo, la mujer del libro, la mujer que traduce, "la mujer que escribe":

Soy la mujer que escribe...

El Lenguaje pertenece a los niños santos. Ellos hablan y yo tengo el poder para traducir. Si yo digo que soy la mujercita de libro, eso quiere decir que un pequeño que brota es mujer y que ella es la mujercita del libro. Así me convierto durante la velada en hongo-mujercita-de-libro (94). ${ }^{16}$

16 "Recuerdo que tuve una visión. Aparecieron unos personajes que me inspiraban respeto. Yo sabía que eran los Seres Principales de los que hablaban mis ascendientes. Ellos estaban sentados detrás de una mesa sobre la que había muchos papeles escritos [...]. Comprendí que los niños me hablaban [...]. En la mesa apareció un libro, un libro abierto que iba creciendo hasta ser del tamaño de una persona. En sus páginas había 
Sor Juana es otra "mujer de la escritura", "mujer del libro". Se empeña en decir que no escribe por su voluntad, que su inclinación es un impulso natural "que Dios puso en mí" ("Respuesta" 1976c: 444), que sólo ha escrito por su gusto "un papelillo que llaman El Sueño":

Demás, que yo nunca he escrito cosa alguna por mi voluntad, sino por ruegos y preceptos ajenos; de tal manera, que no me acuerdo haber escrito por mi gusto sino es un papelillo que llaman El Sueño (470-471).

Si "revuelve" ejemplos de mujeres poetas y mujeres sabias entre los "gentiles", ve a las Sibilas, elegidas por Dios para profetizar los misterios, "en tan doctos y elegantes versos que suspenden la admiración" (461). Sor Juana es una vidente, una visionaria:

Y más, señora mía, que ni aun el sueño se libró de este continuo movimiento de mi imaginativa; antes suele obrar en él más libre y desembarazada, confiriendo con mayor claridad y sosiego las especies que ha conservado del día, arguyendo, haciendo versos, de que os pudiera hacer un catálogo muy grande, y de algunas razones y delgadezas que he alcanzado dormida mejor que despierta (460).

Dictado exterior o dictado del sueño. Aunque éste no sea el lugar para abordarlo, el Sueño es el poema en que se vierte la magia universal —egipcia, hermética, ya no indígena - de sor Juana. Y sin embargo, no es difícil reconocer en sus versos una tradición chamánica:

El poema de sor Juana cuenta la peregrinación de su alma por las esferas supralunares mientras su cuerpo dormía. La tradición del viaje del alma durante el sueńo corporal es tan antigua como el chamanismo. Es una

\footnotetext{
letras. Era un libro blanco, tan blanco que resplandecía. Uno de los Seres Principales me habló y dijo: 'María Sabina, este es el Libro de la Sabiduría. Es el Libro del Lenguaje. Todo lo que en él hay escrito es para ti. El Libro es tuyo, tómalo para que trabajes...' Yo exclamé emocionada: 'Eso es para mí. Lo recibo'. Los Seres Principales desaparecieron y me dejaron sola frente al inmenso Libro [...]. El Libro estaba ante mí, podía verlo pero no tocarlo. Intenté acariciarlo pero mis manos no tocaron nada. Me limité a contemplarlo y, al momento, empecé a hablar. Entonces me di cuenta de que estaba leyendo el Libro Sagrado del Lenguaje. Mi Libro. El Libro de los Seres Principales [...]. Después, en mis posteriores visiones, el Libro ya no aparecía porque su contenido ya lo guardaba en mi memoria" (42-43).
} 
creencia que, a pesar de su inmensa antigüedad, requiere como suposición básica una distinción radical entre lo que llamamos alma y lo que llamamos cuerpo [...]. La idea del alma como una realidad diferente del cuerpo y separable de éste fue, dice Rohde, "una gota de sangre extranjera en el cuerpo de la cultura griega”. Esa gota de sangre, aventura Dodds, fue probablemente escita o tracia (Paz: 472).

Estamos, otra vez, frente al horizonte salvaje o bárbaro de los "gentiles” — su magia, sus "hechicerías”. A orillas del Mar Negro, los argonautas descubrían a Medea, sacerdotisa, hija tal vez de Hécate, figura tutelar de la noche del Primero sueño. Medea la hechicera - la chamana, la de los sacrificios humanos o la india que aparece en la "Loa de Juana Inés": "la diosa / que tres veces hermosa / con tres hermosos rostros ser ostenta" (Sueño 1989: vv. 13-15).

En la Cólquide y Amecameca decían así. Pero, en Huautla, María Sabina cantaba:

Y es que en el medio está el Lenguaje, En esta orilla, en el medio y en la otra orilla está el Lenguaje. Con los nińos veo a Dios, entonces yo canto $[\ldots]$ :

Soy mujer piedra del sol sagrada

Soy mujer piedra del sol dueña

Soy la mujer aerolito

Soy la mujer aerolito que está debajo del agua

$[\ldots]$

Si estoy en la orilla acuática, yo digo: "Soy mujer que está parada en la arena..."

Porque la sabiduría viene desde el lugar donde nace la arena (Estrada: 92-94). 


\section{BibliografíA}

Diccionario de Autoridades. 3 vols. Madrid: Gredos, 1984.

Calleja, fray Diego de. "Narración de la vida y estudios de la poetisa", en Fama y obras posthumas del Fénix de México, Décima Musa, Poetisa Americana [1700]. Edición facsimilar. Pról. Antonio Alatorre. México: Universidad Nacional Autónoma de México, 1995.

Danzas de la conquista. CD. Grabación y notas: Arturo Warman. México: Instituto Nacional de Antropología e Historia, 1997.

Díaz Cíntora, Salvador (ed. y trad.). "La loa de Juana Inés”, en Letras Libres núm. 34 (octubre de 2001). 67-78.

ELIOT, T. S. Los poetas metafísicos y otros ensayos sobre arte y religión. vol. 1. Trad. Sara Rubinstein. Buenos Aires: Emecé, 1944.

Estrada, Álvaro. María Sabina, la sabia de los hongos. México: Siglo XXI, 1977.

Flores, Enrique. La imagen desollada. Una lectura del Segundo sueño de Bernardo Ortiz de Montellano. México: Fondo de Cultura Económica, 2003.

- "La Musa de la Hampa. Jácaras de sor Juana", en Literatura Mexicana II-1991, 7-22.

Gordon Wasson, R. "Presentación” en Álvaro Estrada. Maria Sabina, la sabia de los hongos. México: Siglo XXI, 1977.

Johansson, Patrick. "Sor Juana Inés de la Cruz: cláusulas tiernas del mexicano lenguaje”, en Literatura Mexicana VI-2, 1995, 459-478.

. "Zazanil". La palabra-enigma. Acertijos y adivinanzas de los antiguos nahuas. México: Mc Graw Hill, 2004.

Juana Inés de la Cruz, Sor. El Sueño. Antonio Méndez Plancarte (ed.). México: Fondo de Cultura Económica, 1989.

. "Loa para 'El divino Narciso", en Obras completas III. Autos y loas. Antonio Méndez Plancarte (ed.). México: Fondo de Cultura Económica, 1976a, 3-21 [notas: 503-513].

. "atribuible a la nińa Juana Inés Ramírez de Azvaje". Loa satírica mixta de una comedia representada en el atrio de la Iglesia del Convento Dominico de Nuestra Señora de la Asunción de Amecameca en la festividad de Corpus Christi. Trad. Salvador Díaz Cíntora. Letras Libres núm. 34 (octubre de 2001). 72-78.

- Obras completas I. Lírica personal. Antonio Méndez Plancarte (ed.). México: Fondo de Cultura Económica, 1988.

. Obras completas II. Villancicos. Antonio Méndez Plancarte (ed.). México: Fondo de Cultura Económica, 1976b. 
Juana Inés de la Cruz, Sor. "Respuesta a Sor Filotea de la Cruz", en Obras completas IV. Comedias, sainetes y prosa. Alberto G. Salceda (ed.). México: Fondo de Cultura Económica, 1976c. 440-475.

López Austin, Alfredo. Textos de medicina náhuatl. México: Universidad Nacional Autónoma de México, 1993.

Ortiz de Montellano, Bernardo. Sueños. Una botella al mar. Lourdes Franco (ed.). México: Universidad Nacional Autónoma de México, 1983.

Paz, Octavio. Sor Juana Inés de la Cruz o Las trampas de la fe. Barcelona: Seix Barral, 1982.

Sahagún, fray Bernardino de. Libro Doce, en Historia general de las cosas de la Nueva España. vol. 4. Edición y traducción de Ângel María Garibay. México: Porrúa, 1981, 79-165.

Santamaría, Francisco J. Diccionario de mejicanismos. México: Porrúa, 1983.

Torquemada, fray JuAn DE. Monarquía indiana. vol. 2. Edición facsimilar. Prólogo de Miguel León Portilla. México: Porrúa, 1969.

Vallejo Villa, Augusto. "Acerca de la loa”. Letras Libres núm. 34 (octubre de 2001). 80-81, 119.

Wittgenstein, Ludwig. Comentarios sobre "La rama dorada". Rush Rees (ed.). Trad. Javier Esquivel. México: Universidad Nacional Autónoma de México, 1985. 